\title{
Knowledge And Attitude And Associated Factors To Ward Mental Illness Among Health Professionals Working In Government \& Private Health Facilities At Dilla Town, South Ethiopia
}

\author{
Yetayale Berhanu Wolde ( $\nabla$ yetalb@yahoo.com ) \\ Dilla University \\ Awash AlemboTsebe \\ Dilla University \\ Alem Eskeziya Ayenalem \\ Dilla University
}

\section{Research Article}

Keywords: knowledge, attitude, health professionals, mental illness, health facility

Posted Date: February 10th, 2022

DOI: https://doi.org/10.21203/rs.3.rs-1324178/v1

License: @ (i) This work is licensed under a Creative Commons Attribution 4.0 International License. Read Full License 


\section{Abstract}

Background: - Mental illness is an important determinant of the quality of life of individuals. The negative attitude and negative beliefs toward mental illness even among health professionals is still persisting and lead to widespread stigma and poor help seeking behavior among people with mental illness. In Ethiopia, there is little research done on assessing the knowledge and attitudes of health professionals and this study will narrow this great gap.

Objective: -To assess the knowledge and attitude of health professionals toward mental illness at governmental and private health facilities at Dilla town.

Methods: Facility based cross-sectional study design was employed. The data were collected by using self-administered questionnaire with a total of 126 health professionals. Study participants were drawn using a simple random sampling method. Statistics investigation was done by using SPSS version 21. Descriptive statistics \& logistic regression was done and the result was discussed and presented by frequency tables, graphs, and charts. Variables with $p$-value $<0.05$ were declared as having substantial association between factors and the outcome variables.

THE Result: The level of knowledge on mental illness among health professionals was 43.8\%. Regarding Attitude of Health professionals toward mental illness, $59.6 \%$ were holding an unfavorable attitude. Respondents who have had high awareness have 0.025 times better attitude than those who have no control group. However, this association is not significant. (AOR=0.025, 95\% C.I: $0.035,0.085)$. In this study the level of literacy, contact with a mental ill, individual level of qualification, psychiatric training experience, and long duration of working experience have a strong positive impact on the attitude of health professionals to the psychiatric ills.

Conclusion and Recommendation: The outcome of the study revealed the studied participants had an apparently unfavorable attitudes regarding psychiatric illness associated with lower levels of literacy. This finding was used as the screening attitude by empowering health professionals regarding their knowledge toward mental illness. Over half of the health professionals held an unfavorable attitude toward mental illness. This gives a direction to do more on emphasizing of developing awareness creation and expanding psychiatric training to empower attitude of health professionals toward mental illness.

\section{Introduction}

\subsection{Background}

"Mental illness is a behavioral or psychological syndrome or pattern that occurs in an individual and reflects an underlying psychobiological dysfunction, the consequences of which are clinically significant distress (e.g., a painful symptom) or disability (i.e., impairment in one or more important areas of functioning). It must not be merely an inevitable result of common stressors and losses (for example, the death of a loved one) or a culturally sanctioned response. (1).

350 million people worldwide suffer from mental lines, which are more commonly associated with burden, infirmity, and rapid loss $(2,3)$. While some countries have been successful in fighting stigma and increasing acceptance of mental illness, India and other emerging countries have a lack of knowledge. People who are experiencing mental distress are seen as "odd" and "harmful" by others. The majority of studies have found that people with mental illnesses have more undesirable characteristics and are more likely to be rejected regardless of their behavior. (3) Non-psychiatric health-care workers in the public and private sectors accept responsibility for the fundamental nature of these interferences; they may diagnose psychiatric conditions incorrectly due to a lack of awareness. Discriminatory and defamatory attitudes expressed by health care employees have been linked to the client's mental disorder, resulting in the loss of a mental disorder diagnosis inside a public or private health service. (3) plus (4). 
In both public and private facilities, mentally ill people are regarded as having the capacity to harm others. Despite the ability of district health staff to control mental illness, society's negative stereotypes of people with psychiatric problems cause additional negative feelings, which exacerbate the disease's effects on the affected individual.

Many African people believe that mental disease is caused by a shortage of malevolent spirits in the home. Another commonly held attitude is that mentally ill people are to blame for their own difficulties, particularly those brought on by alcohol or other narcotics. (5) and (6) In most cases, this discrimination denies mental illnesses, the sympathy and consideration that terminally ill people in less developed societies receive. Discrimination indicates that someone is less valuable than others, and this attitude grows among public and private professional health providers in money societies. Psychiatric problems do not always change district health professionals' attitudes about stigma and prejudice. (6).

\subsection{Statement of problem}

Psychiatric disorders are thought to play a significant role in the global impact of illnesses (14 percent). In 2002, 153 million people worldwide suffered from depression, 23 million from schizophrenia, and 91 million from excessive alcohol consumption, according to the World Health Organization (WHO). In both industrialized and developing countries, about $20 \%$ of people suffer from two or more psychiatric or emotional illnesses.

Although only a few nations have been effective in eliminating discrimination and raising awareness about mental health concerns, China and other developing countries have a lack of knowledge. Patients with psychiatric diseases are labeled as "altered" and evaluated adversely by the general public. The bulk of studies have found that people with mental illnesses have more negative characteristics and are more likely to be abandoned (3). Those in Europe and America have similar attitudes about people with mental illnesses, which leads to stigma and prejudice. Psychiatric health facilities are still in the straggler stage, possibly due to a lack of information among public and private health workers about the environmental and physiological factors that influence psychiatric issues. (3), (4), (5), (6).

As a result, the goal of this scholarship is to evaluate the knowledge and attitudes of health professionals regarding psychiatric diseases, this knowledge would be valuable in thinking in health facilities in the east gojam zone because there is a large gap in referring psychiatric patients to hospitals where at least one mental health expert is available. Despite the significant prevalence of mental illness and the profound unfavorable attitude toward people who have it, which may be due to a lack of awareness about the condition, little research on KAP toward PWMI has been done. And the findings of this study will contribute to closing this vast gap.

\section{Methods And Materials}

\subsection{Study period and place}

The study was held from April 16-30, 2016, at Dilla town, two health centers, Dilla university referral hospital, and privet clinics in Dilla town. Dilla town is one of the two city administrations in Gedio zone which was established in 1904 E.C. and it is found at a distance of $365 \mathrm{~km} / \mathrm{s}$ from the capital city, Addis Ababa and it has one main road that passes through the town from Addis Ababa to Moyle. The climatic condition is Woynadega. Its average rainfall is from 1200$1800 \mathrm{~mm}$ per year. The town is surrounded in the north by Sidama, in the south by Wonago, in the east by Bule and Oromia, and in the west by Oromia regional state. The entire area of the region is 135 square kms and the general population is 94,189 of this $46,058(49.9 \%)$ are males and $48,131(50.1 \%)$ are females. The major dominant ethnic group in Dilla town is Gedio followed by others and most of the people speak Gediogna language. The major dominant religious belief in the town is Protestant followed by Orthodox, Muslim and others. The main sources of income for people in the town are trading, micro economic enterprises like cobble stone construction, coffee processing industries, 
flour processing factory, and pottery work. In the town, there are three governmental and four private banks, three insurance company, and eight microfinance enterprises that support the economic development of the people. The town has 1 DU. referral hospital, 2,Governmental health center,1,Non-Governmental health center, 14 private clinics, 4, pharmacy, and 12 drug stores; clean pipe water supply, 1, university, 2,Govermmental college, 2 private colleges, 3, preparatory Schools and 3,high schools, 3, elementary and junior schools, postal, hydroelectric power and telecommunication services.

\subsection{The Study design}

Organization based time-limited (cross-sectional study) design was held.

\subsection{Sampling procedure}

Systematic random sampling after stratified health facilities at Dilla town by using simple randomization using heterogeneity of Government and Privet health facility technique was implemented. If a health professional is found ineligible (based on the inclusion and exclusion criteria), the next health professional was considered.

\subsection{Data collection tool}

The instrument is self-administered and contains three sections. The first component of the survey consisted of 11 questions about socio-demographic variables, health worker experiences, practice, and rank. Section 2 will examine: a) health workers' opinions of the likelihood of psychiatric illness in people they know who are psychiatrically ill; and b) overall health professional interaction and their reported need for it. It includes (a 'yes' or 'no' response format) on the issues that must be addressed in order to continue medical education. Section 3 looks at health care workers' attitudes about psychiatric diseases and the stigma that still exists around depression. There are two ways to code these objects. Some attitude questions are "yes" or "no" questions on a three-point scale (agree=1, neutral=2, disagree=3). Both the Amharic and English versions of the instrument have a total of 60 items. Scores above the mean score indicate a positive attitude/knowledge regarding mental illness, scores below and at the mean value indicate a negative attitude toward mental disease.

\subsection{Data Collection procedure}

Data was collected by using self-administered questioner which is composed of a question on knowledge and attitude toward mental illness among health professionals. The data was collected using structured questionnaires through selfadministered inquiry methods. If the selected patient refused participation, the next eligible respondents fill the questionnaire. Trained supervisors assisted the respondents.

\subsection{Data processing, analysis \& presentation}

After the data was obtained, it was thoroughly examined for completeness and consistency. Before being saved as epidata and then imported to SPSS window version 20 for analysis, it was input, cleaned, and rechecked for completeness, anomalies, and consistency. A descriptive statistics were utilized to compress the outcome and independent factors. Bivariate and multiple logistic regressions were used to evaluate the relationship between socio demographic factors and other independent variables and health professionals' attitudes about mental illness. The variables with a P-value of less than 0.05 confirm the existence of a significant relationship between the independent and dependent variables. The results are provided in the form of frequency tables and graphs, and they are compared to earlier findings. Finally, depending on the study's findings, a complete recommendation is made.

\subsection{Ethical approval}


Ethical clearance and approval was obtained from joint Dilla Town Administration and Dilla University, RDC ethical committee. All Participants in the study was asked for their willingness. The respondents know the reasons why this research was done and explained in the questionnaires to the study participants and provide confidentiality. All the data was gain its great confidentiality is respected.

\section{Results}

\subsection{Socio demographic characteristics of the studied participants}

The study included 126 health professionals with an average age of 33.60 and a standard deviation of 9.59 years. There was a $100 \%$ response rate. More than the usual number of people, 49 (38.9\%), were between the ages of 18 and 24,41 (32.1\%) were between the ages of, 25 and 34, and 36 (28\%) were between the ages of 35 and 49 . In terms of gender, males made up $76.3 \%$ of the participants in the study. The data also shows that $58(45.7 \%)$ of the participants had a diploma, $61(48.3 \%)$ had a first degree, and $8(6.6 \%)$ of the participants had a postgraduate or specialty level education. Considering marital status, $71(56.4 \%)$ of the studied participants were married, $53(42 \%)$ of the studied participants were single, and $2(1.6 \%)$ of the studied participants were divorced for ethnicity, of the studied participants $48(38 \%)$ were Oromo followed by 30(24\%)Amharaandtherest,53(42\%)participantswere(Gedeo16(12.7\%),Gurage14(11.1\%),korre13(10.3\%), and10(7.9\%)were Silicify respectively).Concerning religion of the studied participants, majority of them $73(58 \%)$ were Orthodox Christians and43 (34.1\%) were protestant Christians and 10 (7.9\%) were Muslims. (First Table)

First Table: Socio-demographic of Health professionals study members KA toward psychiatry disorder at Dilla Town, southern ETHIOPIA, 2020. ( $\mathrm{N}=126)$

\subsection{Knowledge level of health professionals on mental illness}

From the studied participants, $43.8 \%$ have a low level of knowledge based on the total knowledge score. The mean for the overall knowledge score is 14.36 and with a standard deviation of 0.49 (Figure: 1)

Figure 3: level of knowledge of mental illness among health professionals in Dilla town, South Ethiopia, 2020

\subsection{Attitude of Health professionals towards mental illness}

With regarding the level of attitude, $59.6 \%$ of the studied participants have a favorable attitudes toward mental illness while $44.4 \%$ of the respondents have an unfavorable attitudes considering the mean attitude score ( $\leq 12.3)$. (Figure 2 )

\subsection{Relation between Knowledge and Attitudes toward mental illness among Health professionals}

As the knowledge score increased by one unit in the studied participants, the attitude scores of them shifted toward favorability by 0.025 times. However, these associations were not statistically significant ( $A O R=0.025,95 \% \mathrm{Cl}: 0.035$, 0.085). Knowledge was entered in the final model; multiple logistic regression by controlling confounding factors. However, the association did not reach statistical significance. Regarding the correlation between Knowledge and attitude, the knowledge scores were directly correlated with attitude scores ( $r=0.032)$ (2 Tables).

2 Table: correlation between attitude and knowledge of studied participants towards mental illness ( $N=126)$

\subsection{Other Factors affecting the attitude of studied participants}

As depicted in Table 3, multiple logistic regressions were used to determine the relationship between health professional knowledge and attitude in life while controlling for relevant variables. In terms of gender, female health professionals 
were more likely than their male counterparts to have a negative attitude (COR $=-1.31,95 \%$ C.I:-2.4,-0.82Those with a higher educational level in the study had a more favourable attitude about mental illness than those with a lower educational level. Respondents with postgraduate and specialist degrees were more optimistic than those with only a bachelor's degree (COR =3.24, 95 present). 4.87, C.I.:1.23 Respondents who had got their first degree had a more favourable attitude than those who had received a diploma (COR $=3.91,95 \%$ C.I:2.53, 4.45). Participants who interacted and got care from psychiatric patients had a more positive attitude toward mental illness than those who did not (COR=2.32, 95 percent C.I:1.91, 2.73). Those who had received psychiatric training exhibited a more positive attitude than those who had not (COR=2.72, 95 percent C.I:0.41, 2.89). Health professionals with more professional experience had a more positive attitude about mental illness than those with less. Respondents with more than ten years of job experience had a three-fold better attitude than those with five to ten years of work experience. (Table 3 )

\section{Table 3.Multiple logistic regression for factors affecting the attitude of health professionals toward mental illness in Dilla Town ( $\mathrm{N}=126)$}

\section{Discussion}

According to the findings, 43.8 percent of health workers had a low awareness of mental illness. This finding is in line with the findings of a 2011 study in the Netherlands called "Do mental health professionals stigmatize their patients?" which found that the most encouraging representations were seen as less characterizing people with psychiatric disorders, while the most negative descriptions were seen as more symbolizing these people (7). This finding is supported by the findings of a study in Nigeria on health professionals' attitudes toward the care of psychiatric patients, which found that health professionals in a district hospital setting expressed concern about caring for mentally ill patients and favored apartheid in the wards (21). The conclusions of this study differ from previous research conducted in England, India, and Columbia (17, 18, and 19). This discrepancy could be explained by the fact that previous studies focused on mental health professionals, who are regarded to be more aware of mental illness than non-psychiatric professionals in my current study. A high percentage of the participants in the survey had a negative attitude about mental illness in terms of overall sentiment among health professionals. It was predicted that increasing awareness of mental illness would enhance health professionals' attitudes toward preventing mental illness when looking at the relationship between amount of knowledge and attitudes toward mental illness, but the data does not support this theory Although various research findings using various methods revealed a significant relationship between the level of literacy and health professionals' attitudes toward mental illness, a snapshot evaluation of studied participants using a crossectional method over a short period of time revealed a small or non-significant relationship (14). There is no evidence in this study that knowing about mental disease has a significant positive impact on health workers' attitudes toward mental illness. Knowledge may not be an important predictor of attitude level in this study, according to the results. This could be due to the limitations of a short data collection period and the use of a crossectional approach to assessing research participants. This result is in line with those of a previous study. The paper "Other People Stigmatize" has been peer-reviewed A lack of awareness and behavior on the part of a few psychiatry practitioners toward people with psychiatric disorders and their families may have contributed to our profession's poor public image and stigma associated with mental illness, according to the study "Attitudes of Mental Health Professionals Toward Patients with Schizophrenia." Surprisingly, their unfavorable views have an impact on how they seek assistance for their own issues (15). However, other investigations in England and India have produced outcomes that are diametrically opposed to those obtained in this study. (11). This paradoxical conclusion is attributed to the better discrimination and stigma reduction strategies, as well as a positive attitude toward psychiatric disease than in Ethiopia.

Other confounding factors influencing survey participants' attitudes are addressed in the following arguments: Females showed a substantially more pessimistic attitude toward mental disease than males. This finding is consistent with findings from research in the United Kingdom on the difficulty of acute care for people with comorbid mental illness (11). 
The psychological backgrounds of women are mirrored in their limited access to resources, their limited position in culturally varied countries like Ethiopia, and their limited role and options in the mental health services seeking behavior and treatment compliance. This consensus report demonstrated that comorbidity increases in prevalence and severity in females, resulting in a higher level of disability. Respondents with higher educational levels have a more favorable view about mental illness than those with lower educational levels, according to the study. This finding matches that of an Indian study on health workers' attitudes about mental illness (16).

This study's findings contradict previous research. "Other People Stigmatize" is a peer-reviewed piper. Attitudes of Mental Health Professionals toward Patients with Schizophrenia" revealed that certain psychiatry professional workers' lack of awareness and behavior toward people with psychiatric disorders and their relatives may contribute to our mental health workers' negative public image and discrimination related to psychiatric disorders $(14,15)$. The findings of this study imply that health workers with more experience in their employment had a more positive attitude toward mentally ill people than those with less experience, based on the participants' perceptions. The findings of a previous identical study conducted in the Netherlands confirm this hypothesis (7).

Study participants who have regular contact and exposure with psychiatric patients have a more favorable view regarding mental illness than those who have less frequent contact. And also this result which is similar with the previous findings of research done in Sweden (15) the authors identified that factors impact staff's awareness and views in a positive way; employer and work area and knowledge and personal contact have an effect on staff's awareness towards the persons they are anticipated to help.

\section{Conclusions And Recommendations \\ 5.1 Conclusion}

Over half of health professionals hold an unfavorable attitude towards mental health problems. Factors related to an unfavorable attitude toward the psychiatric problems among health professionals need to be addressed by mental health intervention programs to improve the life of PWMI.

\subsection{Recommendations of the study}

Based on the above findings, the following recommendations are advised

- Expertise and talent individuals in the department of psychiatry in Dilla University in particular \& in other universities in a general should do great effort to incorporate the research findings as input for policy making and modification on mental health and to expand the training programs which could empower non-psychiatric health professionals to help people with mental illness.

- Implement and plan of community awareness platforms to increase the direction toward the nature of psychiatric disorders, this program should reach all social classes and cultures in: schools, universities, social clubs, religious institutions, and mass media through an outreached health education program.

- Psychiatric institutions should do more roles not only in psychiatric management of patients but also in the expanding of outreach programs and information transmission to non-psychiatric health professionals about the approaching and managing of psychiatric cases holding a positive attitude.

- Ministry of Health should do much on mental illness awareness creation, stigma prevention, and expansion of mental health services to the ground level.

- Expansion of a training program on mental illness to general health professionals 


\section{References}

1. Diagnostic and statistical manual of mental disorders (3rd Ed.).American Psychiatric Association. (1980 Washington, DC: Author.

2. Andrew B. Public Attitudes toward Persons with Mental IIIness.a social and market research firm in Elmsford

3. Ganesh K.KAP toward psychiatric disorder among overall community in south India.

4. National journal of community medicine, 2011,2 (1).

5. DM N.LI Khasakh.V Mutiso2, AW M (KAP) of psychiatric problem among health professional in district hospitals in Kenya: training and policy. African Journal of Psychiatry, 2011

6. Amanda lundvvik G. knowledge and attitude toward mental illness. International journal of allied health science and practice.N.N. Mishra, Triptish B., Nandini K., etal. Knowledge \& attitudes of mental health professionals regarding psychiatric research. Indian J med Res, February 2014.

7. Lauber C, Nordt C, Braunschweig C, Ro“" ssler W. Do mental health professionals stigmatize their patients? .Acta Psychiatry Scand 2006: 113 (429): 51-59.

8. Terje F., Lars J D., Ole R H., Kari K., etal. Collaboration between general practitioners and mental health care professionals. Fredheim et al. International Journal of Mental Health Systems 2011, 5:13

9. Sue B. Lethal discrimination. Rethink Mental IIIness. Lethal discrimination\

10. Else G.,LucyP.,DeborahA.,Melanie D.,etal .no health without mental health .academy of medical royal colleges

11. BelgraveS. Andrews P., TavistockS.Mental illness: stigmatization and discrimination within the medical profession. Royal College of Physicians of London; British Medical Association.

12. Jo-Ann G., Karen-leighE.Challenges in acute care of people with co-morbid mental illness. British Journal of Nursing, 2014, 23(13)

13. Edward j. Other People Stigmatize..But, what about us? Attitudes of Mental Health Professionals Towards Patients with Schizophrenia Istanbul Faculty of Medicine, Department of Psychiatry, Istanbul University, Istanbul, Turkey

14. G. Martens sons. J. W. J Jacobson M. Mental health nursing staff's attitudes towards mental illness. Journal of Psychiatric and Mental Health Nursing

15. V.pandie. Rajiv S., SuPrakash C. knowledge and attitude among non-psychiatric health professionals toward mental illness. Industrial psychiatric journal.20(1)

16. Sara Evans-L, Claire H. , Graham T. Public knowledge, attitudes and behavior regarding people with mental illness in England. The British Journal of Psychiatry (2013)

17. Kim F., Kim U., John A B. ainimere G., etal. Mental health workers' attitudes toward mental illness in Fiji. Australia journal of advancing nursing,25(3)

18. Carlos N., Wulf R., ChristophL.Attitudes of Mental Health Professionals toward People with Schizophrenia and Major Depression. Schizophrenia Bulletin .Oxford University Press

19. Georgina G., Kate Kucharska-P. , John W. Attitudes towards mental disorders and emotional empathy in mental health and other healthcare professionals.BJ psych Bulletin.

20. Attitudes toward Mental Illness - 35 States, District of Columbia, and Puerto Rico, 2007

21. Aghukwa N C. Attitude of health workers to the care of psychiatric patients. Department of Psychiatry, Aminu Kano Teaching Hospital, Kano, Nigeria

22. Jim C., Robert C S., Demoubly K. Attitudes towards mental illness in Malawi. Department of Mental Health, College of Medicine, University of Malawi, Blantyre, Malawi

\section{Tables}


Table 1: Socio-demographic characteristics of Health professionals study participants KA to ward mental illness at Dilla Town, south ETHIOPIA, 2016. ( $\mathrm{N}=126)$

\begin{tabular}{|c|c|c|c|}
\hline \multicolumn{2}{|l|}{ Variable description } & \multirow{2}{*}{$\begin{array}{l}\text { Frequency } \\
76\end{array}$} & \multirow{2}{*}{$\begin{array}{l}\text { Percent (\%) } \\
60.3\end{array}$} \\
\hline Sex & Male & & \\
\hline & Female & 50 & 39.7 \\
\hline \multirow[t]{3}{*}{ Age(in years) } & $18-24$ & 49 & 38.9 \\
\hline & $25-34$ & 41 & 32.5 \\
\hline & $35-49$ & 36 & 28 \\
\hline \multirow[t]{3}{*}{ Marital status } & Single & 53 & 42 \\
\hline & Married & 71 & 56.4 \\
\hline & Others & 2 & 1.6 \\
\hline \multirow[t]{2}{*}{ Educational status } & Diploma & 58 & $(45.7)$ \\
\hline & First degree & 61 & 48.4 \\
\hline \multirow[t]{6}{*}{ Qualification } & Postgraduate \&specialist & 8 & 6.3 \\
\hline & MD & 20 & 15.8 \\
\hline & $\mathrm{HO}$ & 22 & 17.5 \\
\hline & BSC nurse & 19 & 15.1 \\
\hline & Clinical nurse & 37 & 29.4 \\
\hline & Midwife nurse & 21 & 16.7 \\
\hline \multirow[t]{5}{*}{ Working experience } & Less than 2 year & 32 & 25.4 \\
\hline & 2-5 year & 65 & 51.6 \\
\hline & 5-10 year & 23 & 18 \\
\hline & & 6 & 4.8 \\
\hline & Above 10 years & & \\
\hline \multirow[t]{3}{*}{ Religion } & Orthodox & 73 & 58 \\
\hline & Protestant & 43 & 34.1 \\
\hline & & 10 & 7.9 \\
\hline \multirow[t]{2}{*}{ Do you take psychiatric training? } & Yes & 28 & 22.2 \\
\hline & No & 98 & 77.8 \\
\hline \multirow[t]{2}{*}{ contact with psychiatric patient } & Yes & 42 & 33.3 \\
\hline & No & 84 & 66.7 \\
\hline
\end{tabular}

Table 2: correlation between knowledge and attitude of studied participants toward mental illness $(\mathrm{N}=126)$ 


\begin{tabular}{|lllll|}
\hline Study & \multicolumn{2}{c}{ Level of } & attitude & \multicolumn{2}{c|}{ Level of knowledge } \\
\cline { 2 - 5 } Variables & $\mathrm{R}$ & $\mathrm{P}$ & $\mathrm{R}$ & $\mathrm{p}$ \\
\hline Level of attitude & - & - & 0.032 & 0.507 \\
\hline Level of knowledge & 0.032 & 0.507 & - & - \\
\hline
\end{tabular}

Table 3.Multiple logistic regression for factors affected attitude of health professionals toward mental illness at Dilla Town ( $\mathrm{N}=126)$ 


\begin{tabular}{|c|c|c|c|c|c|}
\hline \multirow[t]{2}{*}{ Explanatory characteristics } & \multicolumn{2}{|l|}{ Attitude } & \multirow{2}{*}{ AOR } & \multirow[t]{2}{*}{ P-VALUE } & \multirow{2}{*}{$\begin{array}{l}95 \% \mathrm{Cl} \text { for } \\
\text { COR }\end{array}$} \\
\hline & unfavorab & Favorable & & & \\
\hline Knowledge & & & 0.025 & 0,41 & (0.035,0.085,) \\
\hline \multicolumn{6}{|l|}{ Sex } \\
\hline Male & 35 & 41 & 1.26 & 0.06 & $(0.06,2.58)$ \\
\hline Female* & 21 & 29 & 1.0 & & \\
\hline \multicolumn{6}{|l|}{ Educational level } \\
\hline Diploma* & $29(23)$ & $36(11.8)$ & 1.0 & & \\
\hline First degree & $26(20.63)$ & $35(27.8)$ & 3.24 & 0.001 & $(1.23,4.87)$ \\
\hline Specialist and above & $2(1.5)$ & $6(4.76)$ & 3.91 & 0.001 & $(2.53,4.45)$ \\
\hline \multicolumn{6}{|l|}{ experience(years) } \\
\hline$<2$ & $28(6.6)$ & $23(5.4)$ & 1.0 & & $(0.23,3.45)$ \\
\hline $2-5$ & $78(18.5)$ & $24(5.5)$ & 1.21 & 0.65 & $(0.89,5.67)$ \\
\hline $5-10$ & 134(31.8) & ) 85(19.2) & 3.13 & 0.96 & $(1.41,3.19)$ \\
\hline$>10$ & $24(5.7)$ & $26(6.3)$ & 2.72 & 0.001 & \\
\hline \multicolumn{6}{|c|}{ Do you take psychiatric training? } \\
\hline \multicolumn{6}{|l|}{ Yes } \\
\hline \multirow[t]{2}{*}{ No* } & $59(14)$ & $75(18)$ & 2.72 & 0.001 & $(0.41,2.89)$ \\
\hline & $165(40)$ & 123(29) & 1.0 & & \\
\hline \multicolumn{6}{|c|}{$\begin{array}{l}\text { Contact with mentally ill person in family } \\
\text { in facility }\end{array}$} \\
\hline \multicolumn{6}{|l|}{ Yes } \\
\hline \multirow[t]{2}{*}{ No* } & & & & & \\
\hline & $\begin{array}{l}47(11) \\
77(18)\end{array}$ & & 0.004 & $(1.41,3.19)$ & 0.004 \\
\hline
\end{tabular}




\section{Figures}

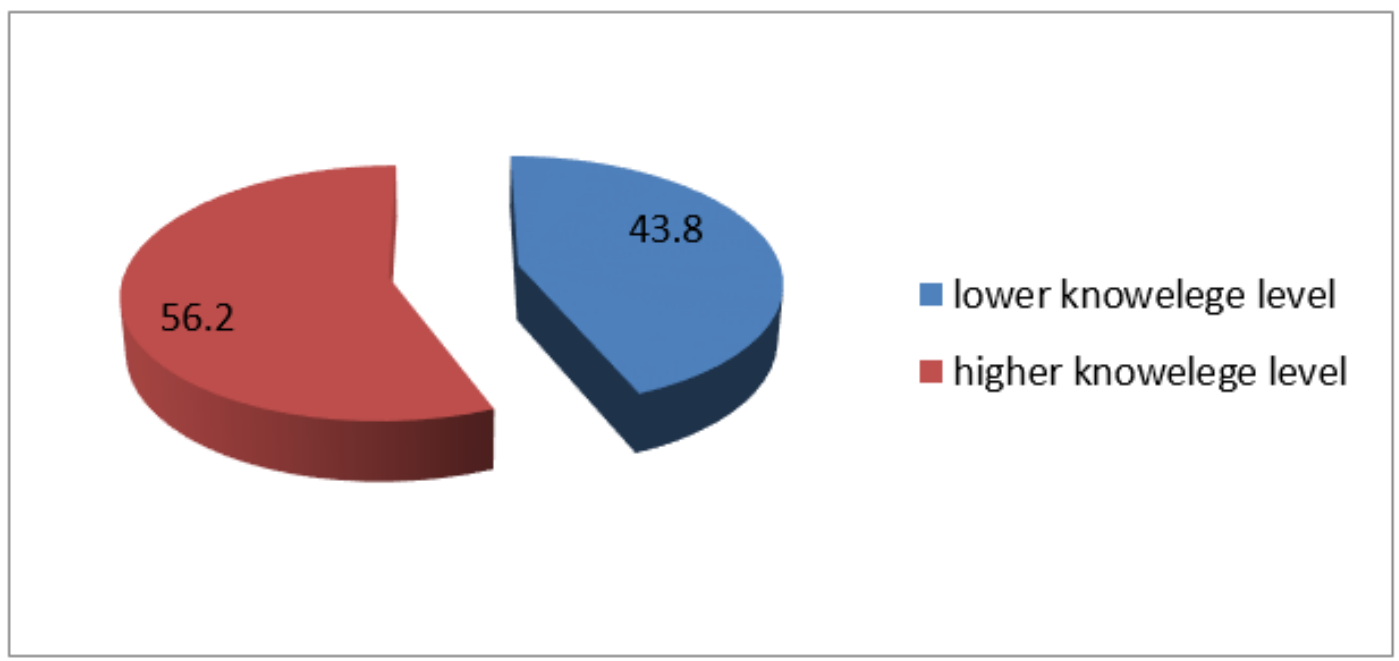

\section{Figure 1}

From the studied participants, $43.8 \%$ have low level of knowledge based on total knowledge score. The mean for the overall knowledge score is 14.36 and with standard deviation of 0.49

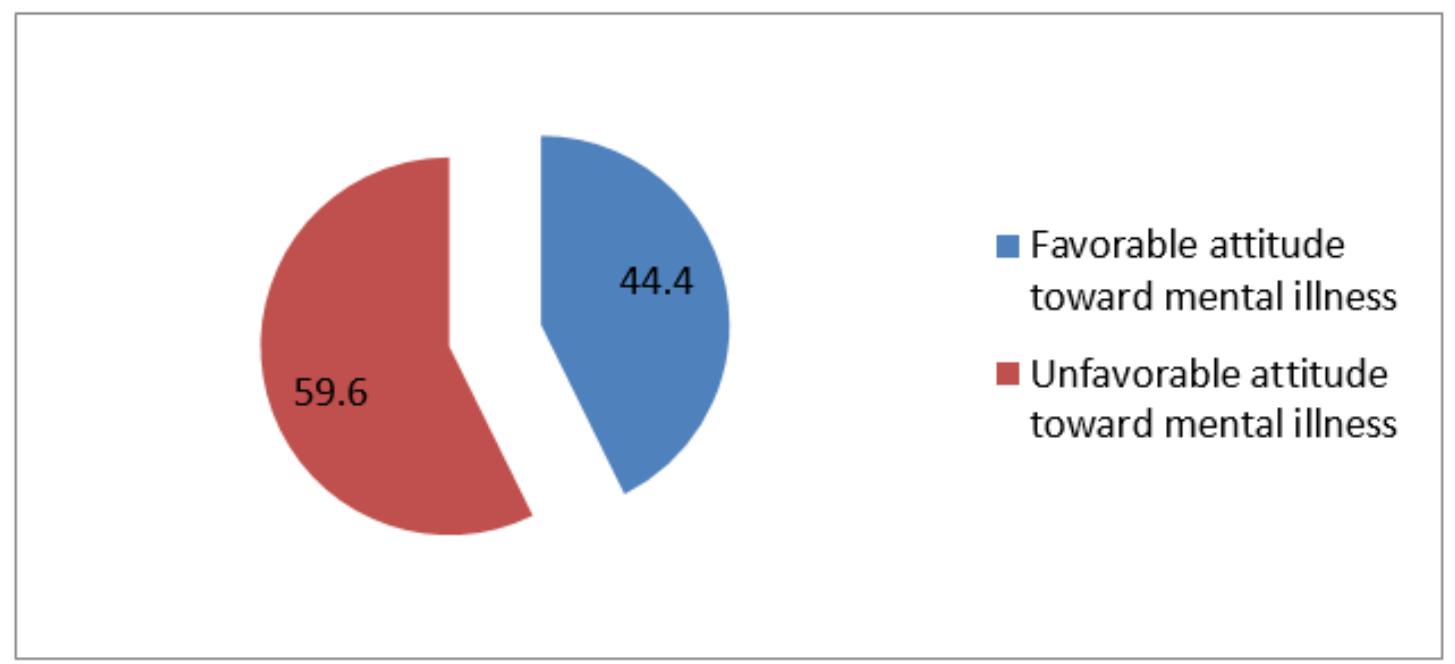

\section{Figure 2}

With regard to level of attitude, $59.6 \%$ of the studied participants have favorable attitude toward mental illness while $44.4 \%$ of the respondents have unfavorable attitude considering the mean attitude score $(\leq 12.3)$. 